\title{
Menstrual hygiene practices among adolescent girls in a resettlement colony of Delhi: a cross-sectional study
}

\author{
Shantanu Sharma ${ }^{1 *}$, Devika Mehra ${ }^{2}$, Charu Kohli ${ }^{1}$, M. M. Singh ${ }^{1}$
}

\author{
${ }^{1}$ Department of Community Medicine, Maulana Azad Medical College, Delhi, India \\ ${ }^{2}$ International Public Health Consultant, Medeon Science Park, Malmo, Sweden
}

Received: 25 February 2017

Accepted: 27 March 2017

\author{
*Correspondence: \\ Dr. Shantanu Sharma, \\ E-mail: shantanusharma145@gmail.com
}

Copyright: (C) the author(s), publisher and licensee Medip Academy. This is an open-access article distributed under the terms of the Creative Commons Attribution Non-Commercial License, which permits unrestricted non-commercial use, distribution, and reproduction in any medium, provided the original work is properly cited.

\section{ABSTRACT}

Background: Menarche is an important milestone in the life of a girl which signifies the onset of fertility in a woman. To understand the health consequences and importance of menstrual hygiene practices among adolescent girls, it is important to study the current practices about the same so that future interventions can be planned accordingly.

Methods: This study adopted a cross-sectional study design. A total of 85 adolescent girls (10-19 years old) were interviewed by the investigator over a period of 3 months (Jan-Mar 2015). Data were analyzed using the software SPSS version 17.

Results: Out of 85 adolescent girls studied, the majority was between 15 to 19 years. In our study $71(83.5 \%)$ out of 85 adolescent girls had already started their menstruation. The mean $( \pm$ SD) age of menarche in the study subjects was $11.4 \pm 5.3$ years. Around 33 out of $71(46.4 \%)$ girls practiced different restrictions during menstruation. Out of 71 (85.9\%) girls used sanitary pads during menstruation. In cases of reused cloth, the place of its drying was observed, responses stated were; outside the house in sunlight in $1(5.8 \%)$ girl, $14(82.2 \%)$ dried them inside the house, and 2 $(11.7 \%)$ girls dried them outside in a dark place.

Conclusions: It is imperative to strengthen the menstrual hygiene management (MHM) programs of the country and have a greater outreach. Multiple strategies need to be used to address this such as education on reproductive health and menstruation provided in schools, media campaign's and improving water and sanitation for improving school retention of adolescent girls and their overall health.

Keywords: Adolescent, Dysmenorrhea, Menarche, Menstruation, Sanitation

\section{INTRODUCTION}

Menstrual hygiene management (MHM), practices related to menstrual hygiene during periods is a serious problem for adolescent girls in low and middle income countries (LMICs). The sustainable development goals $(3,4,5,6)$ are influenced directly or indirectly by poor menstrual hygiene, the achievement of the same is indeed very crucial for the overall development of these young adolescents and the nation at large. ${ }^{1}$

In India, MHM is a serious problem for school going adolescents due to limited or lack of access to products (absorbents) for sanitary hygiene, and lack of safe sanitary facilities. This leads to girls dropping out of school as there is a lack of these basic facilities provided which makes it difficult to manage their menstruation. ${ }^{2}$ The taboos and socio-cultural practices related to menstruation, such as not being allowed to visit holy places and entering the kitchen among others restrictions makes them feel socially ostracised.

Some of the common traditional and unhygienic practices includes use of old clothes as pads after recycling and use of ash or straw endangering menstrual hygiene which has long term implications for their reproductive health. ${ }^{3}$ 
Maintaining good hygiene of women during menstruation is of considerable importance, especially in terms of increased vulnerability to reproductive tract infections (RTI). ${ }^{4}$

India is a country of contrasts, with extreme wealth, poverty and gender-related disparities, which results in significant variation in health and social indicators among girls and women. ${ }^{5}$ There is empirical evidence that of the 113 million adolescent girls, 68 million attend about 1.4 million schools, with poor MHM practices and cultural taboos considered to be impediments to their school attendance. ${ }^{6-8}$ Therefore, it is imperative to recognise the importance of health, education and well-being of the young girls.

Government of India is now making efforts in this direction, the menstrual hygiene scheme was launched in 2011, due to which the front-line functionaries get incentives to mobilize adolescents, provide them with information as well as encourage menstrual hygiene and use of sanitary products. They also promote toilets in homes ensuring separate and cleaner toilets for girls in schools in consultation with village health and sanitation committee. ${ }^{9}$

Scheme for promotion of menstrual hygiene was rolled out in 17 States and in 112 districts through Central supply of free days' sanitary napkins. Till June 2015, over 2.5 crore rural adolescent girls were reached and a total of 6.8 crore sanitary napkins packs were distributed. ${ }^{10}$ Indian public health front line functionaries like Accredited Social Health Activists (ASHA) or Auxillary Nurse Midwives (ANM) can make a substantial difference to menstrual hygiene practices of the community Regarding, how far the scheme has improved the menstrual health and hygiene of adolescents since 4 years of its launch needs an evaluation in further studies.

To understand the consequences and importance of menstrual hygiene practices among adolescent girls, it is important to study the current practices about the same so that future interventions can be planned accordingly. Therefore, the aim of our study was done to assess the menstrual hygiene practices of adolescent girls residing in a resettlement colony in Delhi.

\section{METHODS}

An analytical community based cross sectional study was conducted among adolescent girls in Gokulpuri, Delhi. Gokulpuri is a resettlement colony (colony formed after transportation of people from another area) located in Northeast district of Delhi. There are 4 blocks in the colony with total adolescent girl population around 2006 and the block under study had 350 adolescent girls registered under 5 different Integrated Child Development Service Scheme Centres (ICDS). A list of all adolescent girls available with Anganwadi (ICDS) worker from one of the ICDS centre was prepared and then the visit was made by the female investigator to the residence of each participant. A pre-designed, semistructured and pre-validated questionnaire was used to collect data on menstrual hygiene practices of girls. The tool included questions on socio-demographic factors, menstrual health hygiene practices, access to health system for seeking care for menstruation related issues and social taboos prevalent in their families related to menstruation. A verbal informed consent was obtained from the parent or the legal guardian of the girl before the interview was conducted.

The objectives of the interview and its implications were explained to them and they were assured that confidentiality would be maintained throughout this research. The interviews were conducted by a female investigator so that the girls were comfortable in answering the personal questions. All the data collected were kept fully anonymous and privacy was maintained while conducting the interviews. The interviews were concluded with counselling on menstrual hygiene and referrals were made to the government dispensary in case of any general health related illness or specific menstruation related problem. A total of 85 adolescent girls (10-19 years old) were interviewed by the investigator over a period of 3 months (Jan-Mar 2015). There were 15 adolescent girls that didn't participate because either their houses were found locked or they didn't give consent to participate or unavailability at the time of visit.

\section{Statistical analysis}

Data was analyzed using SPSS software version 17. Proportions and means (Standard Deviation) were used for descriptive analysis. Groups were compared by the chi-square test. Logistic regression was used to assess associations between menstrual practices and the factors affecting them.

\section{RESULTS}

Table 1 shows socio-demographic characteristics of study subjects. Out of 85 adolescent girls studied, majority were in the age between 15 to 19 years. Mean $( \pm$ SD) age was found to be $16( \pm 2.2)$ years. Among all these girls, $81(95.3 \%)$ were Hindus and $4(4.7 \%)$ were Muslims. Most of these girls were educated above high school (58; $68.2 \%)$. In $71(83.5 \%)$ out of 85 adolescent girls studied, the menstruation had already started. The mean $( \pm \mathrm{SD})$ age of menarche in the study subjects was $11.4 \pm 5.3$ years. Further analysis has been done only on 71 participants. Fifty six $(78.8 \%)$ out of 71 girls reported regular periods and $51(71.8 \%)$ of the 71 had average flow (each period lasting 3-5 days) during periods. More than half (38; $53.5 \%$ ) of the girls reported suffering from dysmenorrhea (painful menstrual periods) during menstruation currently. In most $(61.9 \%)$ cases, girls used to consult their mothers for menstruation related issues. Around 16 
girls $(22.5 \%)$ reported that they did not consult anybody. Only $6(8.4 \%)$ did consult doctors about their problem related to menstruation. One-three percent girls consulted either their teachers or friends or Auxillary Nurse Midwives at the health centre as shown in table 2. Around 8 out of $71(11.2 \%)$ girls didn't have toilets at home and had to access community toilet or go elsewhere.

Table 1: Socio-demographic characteristics of study subjects.

\begin{tabular}{|ll|}
\hline $\begin{array}{l}\text { Socio-demographic } \\
\text { characteristics }\end{array}$ & $\begin{array}{l}\text { Frequency } \\
(\%) \text { n=85 }\end{array}$ \\
\hline $\begin{array}{ll}\text { Age } \\
\text { Early adolescence (10-14 years) }\end{array}$ & $21(24.7)$ \\
\hline Late adolescence (15-19 years) & $64(75.3)$ \\
\hline Religion & $81(95.3)$ \\
\hline Hindu & $4(4.7)$ \\
\hline Muslim & \\
\hline Caste & $53(62.4)$ \\
\hline General & $28(32.9)$ \\
\hline Scheduled caste & $4(4.9)$ \\
\hline Other backward class & $4(4.7)$ \\
\hline Education status & $23(27.1)$ \\
\hline Illiterate & $21(24.7)$ \\
\hline Middle level & $25(29.4)$ \\
\hline High school & $12(14.1)$ \\
\hline Secondary level & $60(70.6)$ \\
\hline Graduation & $25(29.4)$ \\
\hline Type of family & $16 \pm 2.2$ \\
\hline Nuclear & $7714 \pm 5047$ (Rs.) \\
\hline Joint & $(123.4 \pm 80.7$ USD) \\
\hline Mean age \pm SD (years) & $6 \pm 2$ \\
\hline $\begin{array}{l}\text { Average monthly family } \\
\text { income } \pm S D\end{array}$ & \\
\hline $\begin{array}{l}\text { Average number of family } \\
\text { members per family } \pm S D\end{array}$ & \\
\hline
\end{tabular}

Table 2: Distribution of adolescent girls according to restrictions imposed during menstruation.

\begin{tabular}{|ll|}
\hline Restrictions & Frequency (\%) \\
\hline Was not restricted $(\mathrm{n}=71)$ & $38(53.5)$ \\
\hline $\begin{array}{l}\text { Restricted for } \\
\text { Praying or Going to } \\
\text { temple/religious places }(\mathrm{n}=33)\end{array}$ & $27(82)$ \\
\hline $\begin{array}{l}\text { Cooking/going and working in } \\
\text { kitchen }\end{array}$ & $10(30)$ \\
\hline Eat certain food items & $3(9)$ \\
\hline Playing or doing exercise & $8(26)$ \\
\hline Routine household work & $7(21.8)$ \\
\hline Whom did you consult for menstrual related issues \\
\hline Mother & $44(61.9)$ \\
\hline Doctor & $6(8.4)$ \\
\hline ANMs & $2(2.8)$ \\
\hline School teacher & $2(2.8)$ \\
\hline Friends & $1(1.4)$ \\
\hline None & $16(22.5)$ \\
\hline
\end{tabular}

Twenty eight out of $71(40.0 \%)$ girls were restricted at home or not allowed to go out during menstruation. Around 33 out of $71(46.4 \%)$ girls practiced different restrictions during menstruation as shown in Table 2 . The girls were restricted from going to temple, eating certain foods, working in kitchen, playing or doing routine household work during the menstrual periods. Menstruation was considered dirty and impure and women during menstruation were considered unhygienic and unclean hence were subjected to restrictions in their daily lives.

Table 3: Distribution of adolescent girls according to their hygienic practices during menstruation.

\begin{tabular}{|c|c|}
\hline $\begin{array}{l}\text { Hygienic practices during } \\
\text { menstruation }\end{array}$ & $\begin{array}{l}\text { Frequency } \\
(\%)\end{array}$ \\
\hline \multicolumn{2}{|l|}{ Type of absorbent $(n=71)$} \\
\hline Sanitary pad only & $45(63.3)$ \\
\hline Cloth only & $18(25.3)$ \\
\hline Both (sanitary pad+cloth) & $8(11.4)$ \\
\hline \multicolumn{2}{|c|}{ Change of the cloth during a period $(n=26)$} \\
\hline Washed the cloth and reuse & $17(65.3)$ \\
\hline Disposed off after single use & $9(34.7)$ \\
\hline \multicolumn{2}{|c|}{ Method of disposal of pad or cloth $(n=62)$} \\
\hline Burn it & $5(8.1)$ \\
\hline Throw it in routine waste & $57(91.9)$ \\
\hline \multicolumn{2}{|c|}{$\begin{array}{l}\text { Wash room facilities for cleaning cloth used as } \\
\text { absorbent at home }(n=17)\end{array}$} \\
\hline Yes & $13(73.0)$ \\
\hline No & $4(27.0)$ \\
\hline \multicolumn{2}{|l|}{ Places of drying $(n=17)$} \\
\hline Outside house in the sunlight & $1(5.8)$ \\
\hline Inside house & $14(82.3)$ \\
\hline Outside house without sunlight & $2(11.7)$ \\
\hline \multicolumn{2}{|c|}{ Daily bath during menstruation $(n=71)$} \\
\hline Yes & $64(90.1)$ \\
\hline No & $7(9.8)$ \\
\hline \multicolumn{2}{|c|}{$\begin{array}{l}\text { Hand washing after visiting toilet during periods } \\
(n=71)\end{array}$} \\
\hline Yes & $70(98.6)$ \\
\hline No & $1(1.4)$ \\
\hline \multicolumn{2}{|l|}{ Hand washing with $(\mathrm{n}=70)$} \\
\hline Water only & $20(28.5)$ \\
\hline Water and soap & $50(71.5)$ \\
\hline \multicolumn{2}{|c|}{ Cleaning of external genitalia $(n=71)$} \\
\hline Yes & $48(67.6)$ \\
\hline No & $23(32.4)$ \\
\hline \multicolumn{2}{|c|}{ Cleaning of external genitalia with $(n=48)$} \\
\hline Water only & $35(72.9)$ \\
\hline Water and soap & $13(27.0)$ \\
\hline \multicolumn{2}{|c|}{ Why were you not using sanitary pads $(n=18) ?$} \\
\hline Mother's advice & $10(55.5)$ \\
\hline Expensive & $8(44.5)$ \\
\hline
\end{tabular}

From Table 3 it can be seen that 53 out of $71(85.9 \%)$ girls used sanitary pads during menstruation. A majority $57(91.9 \%)$ out of 71 girls threw absorbent in routine 
waste after use. Out of 17 girls who reused cloth, $73.08 \%$ reported that washroom facilities were available at home for cleaning cloth used as absorbent. In cases of reused cloth, the places of its drying which were observed, was outside the house in sunlight by $1(5.8 \%)$ girl, $14(82.2 \%)$ dried them inside the house, and $2(11.7 \%)$ girls dried them outside in dark places. When enquired about reasons for non-usage of sanitary pads, 10 out of 18 $(55.5 \%)$ reported that they followed mothers' advice and kept using cloth.

Table 4: Distribution of usage of sanitary napkins among different variables.

\begin{tabular}{|c|c|c|c|}
\hline \multirow[t]{2}{*}{ Variables } & \multicolumn{3}{|c|}{ Sanitary napkin $(\mathrm{n}=71)$} \\
\hline & $\begin{array}{l}\text { Using } \\
\mathrm{N}=53(\%)\end{array}$ & $\begin{array}{l}\text { Not using } \\
\mathrm{N}=18(\%)\end{array}$ & $P$ value \\
\hline \multicolumn{4}{|l|}{ Religion } \\
\hline Hindu & $52(64.2)$ & $15(18.5)$ & \multirow{2}{*}{0.02} \\
\hline Muslim & $1(25.0)$ & $3(75.0)$ & \\
\hline \multicolumn{4}{|c|}{ Monthly Family income } \\
\hline$>7700$ Rs. & $24(66.7)$ & $9(25.0)$ & \multirow{2}{*}{0.2} \\
\hline$<7700$ Rs. & $29(59.2)$ & $9(18.4)$ & \\
\hline \multicolumn{4}{|c|}{ Problems during menstruation } \\
\hline No problem & $27(51.9)$ & $11(21.2)$ & \multirow[b]{2}{*}{0.004} \\
\hline $\begin{array}{l}\text { Dysmenorrhea } \\
\text { present }\end{array}$ & $26(78.8)$ & $7(21.2)$ & \\
\hline \multicolumn{4}{|c|}{ Education status } \\
\hline Illiterate & $2(50)$ & $1(25)$ & \multirow{5}{*}{0.008} \\
\hline Primary & $7(30.4)$ & $7(30.4)$ & \\
\hline High school & $14(66.7)$ & $5(23.8)$ & \\
\hline Secondary & $22(88)$ & $3(12)$ & \\
\hline $\begin{array}{l}\text { Graduation and } \\
\text { above }\end{array}$ & $8(66.7)$ & $2(16.7)$ & \\
\hline
\end{tabular}

Table 5: Multivariate logistic regression analysis between good menstrual hygiene practices and independent variables.

\begin{tabular}{|c|c|}
\hline Variables & $\begin{array}{l}\text { Good menstrual practices }{ }^{\mathrm{a}} \\
\text { Sig Adjusted OR*(95\% CI })\end{array}$ \\
\hline \multicolumn{2}{|c|}{ Visit to Anganwadi } \\
\hline Yes & \multirow{2}{*}{$\begin{array}{ll}0.005 & 9.8(2.0-48.0) \\
0.0^{\mathrm{b}} & \end{array}$} \\
\hline $\mathrm{No}^{\mathrm{c}}$ & \\
\hline \multicolumn{2}{|l|}{ Family income } \\
\hline$>7714 \mathrm{Rs}$ & \multirow[t]{2}{*}{$2.9(0.6-13.0)$} \\
\hline$<7714$ Rs. $^{\mathrm{c}}$ & \\
\hline \multicolumn{2}{|c|}{ Discarding napkins } \\
\hline Safe disposal & \multirow[t]{2}{*}{$41.3(5.0-336.4)$} \\
\hline No safe disposal & \\
\hline \multicolumn{2}{|c|}{ Experience of problems during menstruation } \\
\hline Dysmenorrhea & \multirow[t]{2}{*}{$0.1(0.02-0.7)$} \\
\hline Nothing ${ }^{\mathrm{c}}$ & \\
\hline \multicolumn{2}{|l|}{ Type of family } \\
\hline Nuclear & \multirow[t]{2}{*}{$3.9(0.8-19.5)$} \\
\hline Joint $^{\mathrm{c}}$ & \\
\hline
\end{tabular}

On the contrary $8(44.5 \%)$ girls out of 18 found them expensive hence they didn't use it. Fifty-six out of 85 $(78.8 \%)$ girls used to visit anganwadi for nutrition and other services. Sanitary napkins were more commonly used among Hindu girls compared to Muslim girls $(\mathrm{p}=0.02)$ and among educated girls compared to illiterate $(\mathrm{p}=0.008)($ Table 4).

A multivariate logistic regression analysis was done to find association between good menstrual practices (use of sanitary napkins, cleaning of external genitalia during periods and bath during periods or any of them) and visits to Anganwadi, type of family, disposal of napkins, family income etc. as shown in Table 5. Visit to Anganwadi $\mathrm{OR}=0.00595 \%$ CI 9.8 (2.0-48.0) and low prevalence of dysmenorrhea OR=0.02 95\% CI $0.1 \quad(0.02-0.7)$ were found to be significantly associated with practising good menstrual hygiene.

\section{DISCUSSION}

In the present study, mean age of menarche in girls was $11.4 \pm 5.3$ years. This was lesser than that reported in earlier studies. A study by Patavegar et al among school going adolescent girls in urban Delhi in 2014 reported mean age of menarche as $12.7 \pm 1$ years. ${ }^{11}$ Similarly study by Dinesh Kumar et al reported it as 13.02 years and Nair et al from Delhi reported it to be as 13.6 years. ${ }^{12,13}$ The previous two mentioned studies were community based studies similar to present study which gives a more representative picture of the issue. It has been established that menarche is also influenced by factors such as socioeconomic class and genetic factors. ${ }^{14}$ Studies have shown that the age at menarche has been decreasing generally in many countries with a mean age at menarche ranging from 12 to 13 years in the majority of developed countries. $^{15}$

A number of studies were conducted to review the secular trend in age of menarche in India and associated factors with it. An analysis conducted by Pathak PK et al found that there was a reduction of nearly one month per decade decline in age at menarche among Indian women. The factors for the same were significantly associated with the area of residence, geographic region, linguistic groups, educational attainment, wealth status, caste and religious affiliations among Indian women. ${ }^{16}$ Various mechanisms have been explained like role of obesity among girls especially in urban areas which leads to altered levels of leptin, IGF-1, ghrelin and most importantly insulin which are related to energy availability and body size which have a permissive role in the initiation of puberty. ${ }^{17}$ This could be the reason that India although not a developed country is experiencing the same phenomenon of declining age of menarche as in developed nations. Increasing prevalence of obesity among adolescent girls due to sedentary lifestyle could be one major factor. In the present study, however socioeconomic status was not significantly associated with age at menarche $(p=0.21)$. Fifty-six $(78.8 \%)$ out of 
71 reported regular periods (3-5 days) and they all had average flow during periods. The results are similar to a study by Juyal R et al ${ }^{18}$ conducted in Dehradun in 2014 among unmarried adolescent girls in which $74.6 \%$ girls reported having an average flow of 3-5 days and around two third having normal bleeding. The present study highlighted the medical problems faced by adolescent girls during menstruation. It was observed that dysmenorrhea was experienced by $53.5 \%$ of the girls. But other studies have reported higher prevalence of dysmenorrhea among adolescent girls. In a study by Juyal $\mathrm{R}$ et al it was observed among $64.9 \%$ girls whereas $63.75 \%$ prevalence was reported in a study by Nair et al among rural unmarried adolescent girls in East Delhi. ${ }^{13,18}$ Patavegar et $\mathrm{al}^{11}$ in his study reported prevalence of medical problems faced during menstruation as high as $71.59 \%$. More than two-third $(66 \%)$ of the girls consulted mothers first for any of their menstrual related health issue whereas doctor was consulted by only $8.5 \%$ girls. This is in contrast to observations from a study by Paul et al from 5 districts each, from 5 states of India (Delhi, Karnataka, Assam, Madhya Pradesh and Uttar Pradesh) in which doctors were approached by maximum (78\%) girls for their menstrual related morbidity. ${ }^{19}$

Different restrictions were imposed on girls during menstrual periods. About $40 \%$ girls were not allowed to move out during menstrual periods. Similarly, $46.5 \%$ girls practised different restrictions, the most common of which was restriction to pray or worship in temples during periods (82\%). Girls were also not allowed to stay in kitchen or cook food $(30 \%)$ or eat certain food items like curd, pickles $(26 \%)$ etc. The findings were consistent with other studies. ${ }^{11,20-22}$ The consideration of menstruation as social taboo is so strong that even literate females find it difficult to go against the restrictions, owing to such strong socio-cultural beliefs and practices.

Majority $(63.3 \%)$ of the girls were using sanitary pads while cloth was used by $25.3 \%$ and cloth and pads both were used by $11.4 \%$ girls. The practice of using pads is less than that reported from study by Patavegaret al from Delhi $(85.92 \%)$ and Shamima et al (82.2\%) from Bengal but similar to a study done by Subash Thakre $(60.58 \%)$ in northern India. ${ }^{11,20,22}$ Reusing the cloth after wash was practised by $11.52 \%$ girls similar to what has been reported by Patavegaret al $(11.82 \%) .{ }^{11}$ Low-cost sanitary pads that are disposable is a simple and innovative means of improving menstrual hygiene and for addressing a broader set of problems related to Menstrual Hygiene and health. ${ }^{7,23}$

A safe and hygienic practice of throwing the used cloth after single use was done by $8.7 \%$ of the girls. Regarding drying of washed cloth, $82.2 \%$ dried the cloth inside the house after washing which is not a good practice since exposure to sun kills germs and prevents infections. This practice as observed in the current study was poor than that reported by Patavegaret al where a lesser number of girls $(44.25 \%)$ used to dry cloth inside the house and rest of the girls dried it outside in the sun. ${ }^{11}$ The girls who use cloth are more prone to develop genital tract infection as compared to those using sanitary napkins. Repeated use of unclean cloth and improper drying of cloth, before reuse, results in harbouring of micro-organisms resulting in the spread of vaginal infections, viz., white discharge, itching and burning during menstrual period. ${ }^{24}$ Approximately $92 \%$ girls enrolled in this study reported to throw used pads and cloths along routine waste.

The link between socioeconomic status and reproductive health has been established before, and it is plausible that increased wealth is associated with overall better hygiene resulting in lower susceptibility to genital infections. ${ }^{25}$ However, the current study failed to illicit such association between good menstrual hygiene practices and socioeconomic status $(\mathrm{p}>0.05)$. The association of menstrual problems (dysmenorrhea) with access to WASH facilities (toilet at home for changing pads, washing cloth and drying in sun) was not found significant $(\mathrm{p}>0.05)$.

In the present study $90 \%$ girls took regular bath during periods. Another study by Juyalet al in Uttarakhand reported regular bathing during periods among 64\% of the girls only. ${ }^{26}$ Almost all girls (98\%) did wash hands after going to toilet during episodes of periods but soap was used by only $27 \%$ girls. During periods $67.6 \%$ girls did clean external genitalia. The study by Thakre $\mathrm{S}$ in Nagpur among school going adolescent girls reported this habit being practised by $58.09 \%$ of them whereas similar study by Patavegaret al among school girls in Delhi observed it being practiced by as low as $34.32 \%$ girls. ${ }^{11,20}$

Nearly $79 \%$ of the girls were availing services from Anganwadi workers in this study. It is similar to what has been reported by Sharma et al in his study among adolescent girls from Urban Belagavi in which $77 \%$ girls were regularly obtaining services from Anganwadi workers. ${ }^{27}$ The study also reported that only $17 \%$ were receiving sanitary pads from Anganwadi centres. In the present study good menstrual practices like use of sanitary pads and cleaning of external genitalia during periods was significantly associated with Anganwadi visits $\mathrm{OR}=0.005$ 95\% CI 9.8 (2.0-48.0). There are limited studies to report effectiveness of Anganwadi workers in determining good hygienic practices among adolescent girls. The study by Paul et al revealed the attribute of ICDS (Anganwadi) in improving menstrual hygiene practices among adolescent girls over a period of 5 years. ${ }^{19}$ Another study in this regard conducted by Jessy et al among adolescent girls from Kerala has emphasized on the role of ICDS in improving knowledge and reproductive health of girls. ${ }^{28}$

\section{Limitations}

Since the study was conducted in North East Delhi with a small sample size, hence the results cannot be generalized. But to accommodate for small sample size, 
homogenous sample was collected (girls of similar age group and similar socio-demographic characteristics from same locality). The study aimed at assessing only the practices of the adolescents regarding menstrual hygiene and didn't focus on knowledge and attitude which if addressed could have highlighted more on the role of Anganwadi or other frontline functionaries in menstrual health of girls. The study period was just for 3 months and that too in winter season which might have led to bias due to seasonal change in practices compared to if the data collection would have been distributed round the year. This is an observational study therefore; we cannot determine causality of the observed associations. Residual confounding may have remained when adjusting for self-reported risk factors, especially in relation to menstrual practices. We also did not adjust for other possible related factors, such as sexual practices or urogenital infections while analysing the effect of sanitary practices on health

\section{CONCLUSION}

The overall results from our study conclude that though the prevalence of dysmenorrhea was less but the menstrual hygiene practices were poor among girls they had to face restrictions and social taboos related to menstruation. Visit to an anganwadi centre was a factor associated with improved menstrual hygiene practices. Education to girls about the facts of menstruation, physiological implications, significance and proper hygienic practices during menstruation is the need of the hour. It is also required to bring them out of traditional beliefs, taboos, misconceptions and restrictions. Focus group discussions, mass media campaigns, and inclusion of sex education in schools are required to overcome taboo aspect of menstruation. All mothers should be encouraged to break their inhibitions about discussing with their daughters regarding menstruation and menstrual hygiene. Menstrual hygiene scheme run by Government of India should be implemented effectively and regular evaluation of the same is required.

\section{Funding: No funding sources}

Conflict of interest: None declared

Ethical approval: The study was approved by the Institutional Ethics Committee

\section{REFERENCES}

1. Menstrual Hygiene and the Sustainable Development Goals. Available from: http://simavi.org/duointerview/menstrual-hygiene-sustainable-devt-goals. Accessed Oct 2, 2016.

2. NRHM. Operational guidelines. Promotion of menstrual hygiene among adolescent girls (1019years) in rural areas. Ministry of Health and Family Welfare;2011:9.

3. Selvi KT, Ramachandran S. Socio-cultural taboos concerning menstruation: A micro level study in the
Cuddalore District of Tamil Nadu, India. Int $\mathbf{J}$ Scientific Res Publica. 2012;2(8):1-7.

4. Singh MM, Devi R, Garg S, Mehra M. Effectiveness of syndromic approach in management of reproductive tract infections in women. Indian $\mathrm{J}$ Med Sci. 2001;55(4):209-14.

5. Prusty RK, Kumar A. Socioeconomic dynamics of gender disparity in childhood immunization in India. PLoS ONE. 1992-2006. 2014;9:e104598.

6. Mahon T, Fernandes M. Menstrual hygiene in South Asia: a neglected issue for WASH (water, sanitation and hygiene) programmes. Gend Dev. 2010;18:99113.

7. Thakur H, Aronsson A, Bansode S, Lundborg CS, Dalvie S, Faxelid E. Knowledge, practices, and restrictions related to menstruation among young women from low socioeconomic community in Mumbai, India. Front Public Health. 2014;2:72.

8. Muralidharan A, Patil H, Patnaik S. Unpacking the policy landscape for menstrual hygiene management: implications for school Wash programmes in India. Waterlines. 2015;34:79-91.

9. National Rural Health Mission. Training module for ASHA on menstrual hygiene. Ministry of Health Family Welfare;2011:101-21.

10. Ministry of Health Family Welfare. Annual report 2015-16. Government of India;2016:34.

11. Patavegar BN, Kapilashrami MC, Rasheed N, Pathak R. Menstrual Hygiene among Adolescent School Girls: An In-Depth Cross-Sectional Study in an Urban Community. Int $J$ Health Sci Res. 2014;4(11):15-21.

12. Kumar D, Goel NK, Puri S. Menstrual pattern among unmarried women from northern India. J Clini Diag Res. 2013;7(9):1926-9.

13. Nair P, Grover VL, Kannan AT. Awareness and practices of menstruation and pubertal changes amongst unmarried female adolescents in a rural area of East Delhi. Indian J Comm Medic. 2007;32:156-7.

14. Gupta S, Sinha A. Awareness about reproduction and adolescent change school girls of different socioeconomic status. J Obstet Gynecol India. 2006;56(4):324-8.

15. Padez, Rocha, MA. Age at menarche in Coimbra (Portugal) school girls: A note on secular changes. Ann Hum Biol. 2003;30(5):622-32.

16. Pathak PK, Tripathi N, Subramanian SV. Secular Trends in Menarcheal Age in India-Evidence from the Indian Human Development Survey. PLoS One. 2014;9(11):e111027.

17. Khadilkar VV, Stanhope RG, Khadilkar V. Secular trends in puberty. Indian Pediat. 2006;43:475-8.

18. Juyal R, Kandpal S, Semwal J. Menstrual Hygiene and Reproductive Morbidity in Adolescent Girls in Dehradun, India. Bangladesh J Med Sci. 2014;13(02):170-4.

19. Paul D, Patnik R, Gopalakrishnan S. Improvement in knowledge and practices of adolescent girls on reproductive health with focus on hygiene during 
menstruation in five years. Health Populat Perspec Issues. 2014;37(1\&2):1-14.

20. Thakre SB, Thakre SS, Reddy M. Menstrual hygiene: knowledge and practice among adolescent school girls of Saoner, Nagpur district. J Clini Dia Res. 2011;5(5):1027-33.

21. Goel MK, Mittal K. Psycho-social behavior of urban Indian Adolescent girls during menstruation. Australasian Med J. 2011;4(1):49-52.

22. Yasmin S, Manna N, Mallik S. Menstrual hygiene among adolescent school students: An in-depth cross-sectional study in an urban community of West Bengal, India. IOSR.2013;5(6):22-6.

23. Crofts T, Fisher J. Menstrual hygiene in Ugandan schools: an investigation of low-cost sanitary pads. 2012;2(1):50-8.

24. Dube S, Sharma K. Knowledge, attitude and practice regarding reproductive health among urban and rural girls: a comparative study. Ethno Med. 2012;6(2):8594.

25. World Health Organization. Closing the Gap in a Generation: Health Equity Through Action on the Social Determinants of Health: Commission on
Social Determinants of Health Final Report: World Health Organization;2008.

26. Juyal R, Kandpal S, Semwal J, Negi KS. Practices of menstrual hygiene among adolescent girls in a district of Uttarakhand. Indian J Commu Health. 2012;24(2):124-8.

27. Sharma M, Angolkar M, Narasannavar A, Murthy S, Oza M. Perception towards functioning of Anganwadis and utilization of ICDS services by the adolescent girls of Urban Belagavi-A cross sectional study. Int J Adv Res. 2015;3(6):1431-5.

28. Jessy KC, Antony P. Responsiveness on Reproductive health among adolescent girls: A study based of integrated child health development scheme (ICDS). Vistas. 2014;3(1):75-82.

Cite this article as: Sharma S, Mehra D, Kohli C, Singh MM. Menstrual hygiene practices among adolescent girls in a resettlement colony of Delhi: a cross-sectional study. Int J Reprod Contracept Obstet Gynecol 2017;6:1945-51. 